\title{
Developing a Questionnaire and Evaluation Methods for a High School Rocket Program
}

\section{Mr. Ibrahim Halil Yeter, Texas Tech University}

Ibrahim H. Yeter is currently a PhD candidate in the Curriculum and Instruction program at the College of Education, and at the same time, he is pursuing his Master's degree in Petroleum Engineering at Texas Tech University. He is highly interested in conducting research within the Engineering Education framework. Mr. Yeter plans to graduate in December 2016 with both degrees and is looking forward to securing a teaching position within a research university and continuing his in-depth research on Engineering Education.

He is one of two scholarships awarded by NARST (National Association for Research in Science Teaching) to attend the ESERA (European Science Education Research Association) summer research conference in České Budějovice, Czech Republic in August 2016. In addition, he has been named as one of 14 Jhumki Basu Scholars by the NARST's Equity and Ethics Committee in 2014. He is the first and only individual from his native country and Texas Tech University to have received this prestigious award. Furthermore, he was a recipient of the Texas Tech University President's Excellence in Diversity \& Equity award in 2014 and was the only graduate student to have received the award, which was granted based on outstanding activities and projects that contribute to a better understanding of equity and diversity issues within Engineering Education.

Additional projects involvement include: Engineering is Elementary (EiE) Project; Computational Thinking/Pedagogy Project; Rocket Project of SystemsGo; World MOON Project; East Lubbock Promise Neighborhood (ELPN) Project; and Robotics. Since 2013 he has served as the president of the Nu Sigma chapter of Kappa Delta Pi: International Honor Society in Education and was the founding president of ASEE Student Chapter at Texas Tech University. He can be reached at ibrahim.yeter@ttu.edu.

\section{Dr. Hansel Burley, Texas Tech University}

Dr. Burley is a professor of educational psychology. His research focus includes college access, diversity, and resilience in youth. Recently he has served as the evaluator for multiple STEM projects.

\section{Mr. Terrance Denard Youngblood, Texas Tech University}

Terrance D. Youngblood is a doctoral student in Educational Psychology at Texas Tech University, specializing in the effective evaluation and assessment of educational outreach programs and workforce development.

\section{Mr. Casey Michael Williams, Texas Tech University}

I am currently a second year PhD student in educational psychology. I spent 2 years teaching environmental science, chemistry and biology to high school students in Kansas City through Teach For America. My interests lie with designing educational initiatives that highlight the importance of STEM education for the future of learning and motivation. 


\section{Developing a Questionnaire and Evaluation Methods for a High School Rocket Program}

\section{Introduction}

Recently, there has been a push to increase students' interest and attitudes in science, technology, engineering and mathematics (STEM) fields in the United States, particularly in engineering. The importance of STEM has been emphasized by numerous researchers (e.g., Cantrell, Pekcan, Itani, \& Velasquez-Bryant, 2006; Hunter, 2006; Mayo, 2007; Sánchez \& Olivares, 2011) along with several organizations (e.g., Accreditation Board for Engineering and Technology [ABET], National Academy Press [NAE], Next Generation Science Standards [NGSS]). According to ABET Criteria, "the engineering sciences have their roots in mathematics and basic sciences but carry knowledge further toward creative application. These studies provide a bridge between mathematics and basic sciences on the one hand and engineering practice on the other. Engineering design is the process of devising a system, component, or process to meet desired needs. It is a process in which the basic sciences, mathematics, and the engineering sciences are applied to convert resources optimally to meet these stated needs." Likewise, a rocket project in the southern United States embraces adolescent students' needs to have a project-based learning experiences designed to provide an opportunity to improve multidisciplinary domains (e.g. physics, mathematics, atmospheric science) teamwork, communication, project management, and problem solving skills, as well as, focusing on immersion in a STEM environment that will enhance life-long active learning.

Today, our nation faces a paradox that companies need employees with STEM related knowledge, but the workforce is lacking in this department. In fact, all of the 30 fastest growing occupations in the next decade will involve STEM (Change the Equation, 2013). Additionally, these are high paying jobs with median earning ranging from $\$ 80,000$ for mining and mineral engineering to $\$ 120,000$ for petroleum engineers (Carnevale, Strohl, \& Milton, 2009). However, in one ACT study (ACT, 2011) that is consistent with many others, only $25 \%$ of high school students met all the college readiness benchmarks set by the ACT in English, reading, science, and mathematics. While $45 \%$ met the mathematics benchmark, only $30 \%$ met the readiness benchmark in science.

Consequently, the STEM related workforce gap between the needs of employers and skills of the workforce is in turmoil. The Lemelson-MIT Invention Index that surveys American's perceptions' about invention and innovation found that teens and young adults are highly interested in pursuing STEM careers. However, 34\% said that that they did not know much about the fields, $33 \%$ said the fields were too challenging, and $28 \%$ believed that they were not well-prepared to pursue these fields. Still, $85 \%$ of students said that they wished they knew more about STEM fields. Thus, the interest in STEM related fields is there, but the environments that teach it lack in motivating students to pursue those career choices.

According to the same report, late elementary, middle and junior high school age teens (12-17 years of age) reported the most effective way to engage in science was through hands-on 
active learning, STEM related activities outside the classroom. For instance, STEM field trips, building things and conducting experiments were rated as the best ways to interest them in STEM subjects. Finally, the report found that teachers who enjoy teaching STEM subjects and STEM mentors play a powerful role in increasing students' interest in STEM.

The need to increase student STEM readiness and interest in STEM is great. Programs that combine hands-on problem solving and teamwork, plus highly motivated, qualified and effective teachers and mentors (e.g., Holden, Marrett, \& Suresh, 2013; Katehi, Pearson, \& Feder, 2009) are what students say will be effective. X's vision provides hands-on activities in an inquiry-based classroom environment, with the "classroom" extended to shops and launch pads in the field. The program also provides training and support for teachers who participate in the program. In particular, teachers learn a brand of Socratic questioning that shifts the learning environment from teacher to student. By allowing the students to formulate their own questions, metacognitive strategies and deep-thinking are utilized. Students are able to visualize their successes and failures from start to finish and rejoice in the process no matter the outcome.

\section{Program Description}

SystemsGo is an aerospace program that develops high school students' skills in the areas of rocket design, development, testing, analysis, and innovation. Additionally, students learn physics, mathematics, and pre-engineering skills by conceiving, constructing, and launching rockets. Students learn about the laws of rocket stability and fluid dynamics, while trying to prepare for unforeseen variables associated with both the internal design of the rocket and the external environment. After 3 years of conceiving, designing and implementing a rocket design, participants are able to operate and launch their rockets at the White Sands Missile Range. Approximately 50 high schools in the southern United States participate in this program.

The students in the program possess a diverse range of backgrounds and prior learning experiences and are able to effectively communicate despite these challenges. Students gain hands-on active learning experience in problem solving, testing, data analysis, teamwork, and project management. The program also prepares teachers to use investigative learning and critical thinking strategies in the classroom. Interestingly, high school science teachers dominate the population of teachers. However, teachers can come from any field taught at the high school to fulfill team goals of problem solving during the project. The SystemsGo program includes students and teachers from urban, suburban, and rural schools. The program encourages diverse students in their classes, with diversity being defined across a broad spectrum such as ethnic, socioeconomic, academic skill, and diversity of interest.

\section{How the Program Works}

SystemsGo's Rocket Project provides low cost teacher training for the interdisciplinary teams that are chosen. The focus of the training is to increase teachers' pedagogical sophistication, using inquiry and project-based teaching methods and Socratic questioning 
techniques. The instructional design includes integrating STEM skills with those of communication, teamwork, critical thinking, active learning and leadership. Teacher training includes a three-step curriculum with the following project targets;

i. Tsiolkovsky: Production of a rocket that can lift a 1 pound payload a mile high

ii. Oberth: Production of a rocket that can break the speed of sound, reaching 10-13,000 feet.

iii. Goddard: Production of a rocket that carries a research payload 19 miles high and is launched at White Sands Missile Range.

At the Tsiolkovsky step, the teacher training is focused on implementing the curriculum, locating and acquiring the needed materials in a timely manner, fabricating parts, strengthening teamwork and communication skills, managing funding/schedules and developing rockets capable of stable flight. Once a school achieves success at the Tsiolkovsky step, it moves to the Oberth step. At this step, the curriculum focuses on incorporating all the knowledge and experience from the first year, while students work toward achieving a greater understanding of mass fractions and aerodynamic loads. Students also develop skills needed to design and construct the rocket vehicle. The curriculum at the Goddard step focuses on understanding what is needed to develop high altitude flight time as well as reflecting on the entire process and the learning it took to get there. SystemsGo charges students with designing and producing rockets from nose cone to nozzle. The products are about 20' in length, 1' in diameter, weighing about 500lbs. A logic model for the program is provided in Figure 1.

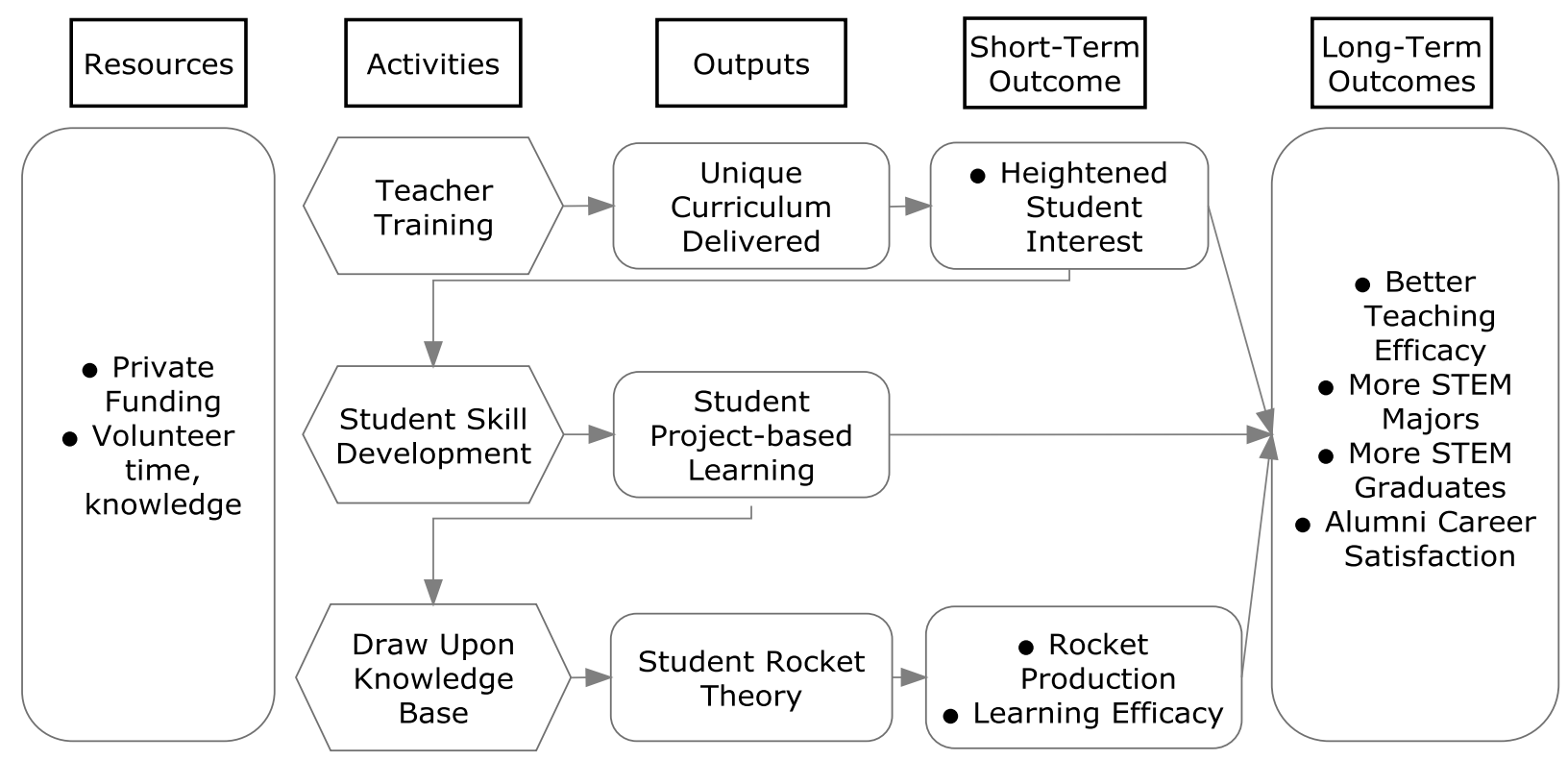

Figure1. Z-Chart Logic Model for SystemsGo Program 


\section{Theoretical Framework for STEM Interest Questionnaire (STEM IQ)}

Social Cognitive Career Theory (SCCT) (Lent, Brown, \& Hackett, 2002) is grounded in Bandura's (1986) Social Cognitive Theory, with the emphasis on how career and academic interests mature, how career choices are developed and how these choices are turned into action (see Figure 2). This is accomplished in three ways: self-efficacy, outcome experiences, and goals. Self-efficacy is defined as the beliefs people have about their ability to successfully complete the steps required for a given task. Individuals develop their sense of self-efficacy from personal performance, learning by example, social interactions and reflections on how they feel in certain situations. Outcome expectations are the beliefs related to consequences of performing a specific behavior. Typically, outcome expectations are formed through past experiences, either direct or vicarious and the results of these experiences. Goals are deemed as the decisions to begin a particular activity or future activity, which are organized or sustained based on the goals set (Lent, Brown, \& Hackett, 1994). Significant research has found that student goals to pursue STEM majors and careers are excellent predictors of choosing those careers (Lapan, Shaughnessy, \& Boggs, 1996; Lent et al., 2003; Lips, 1992).

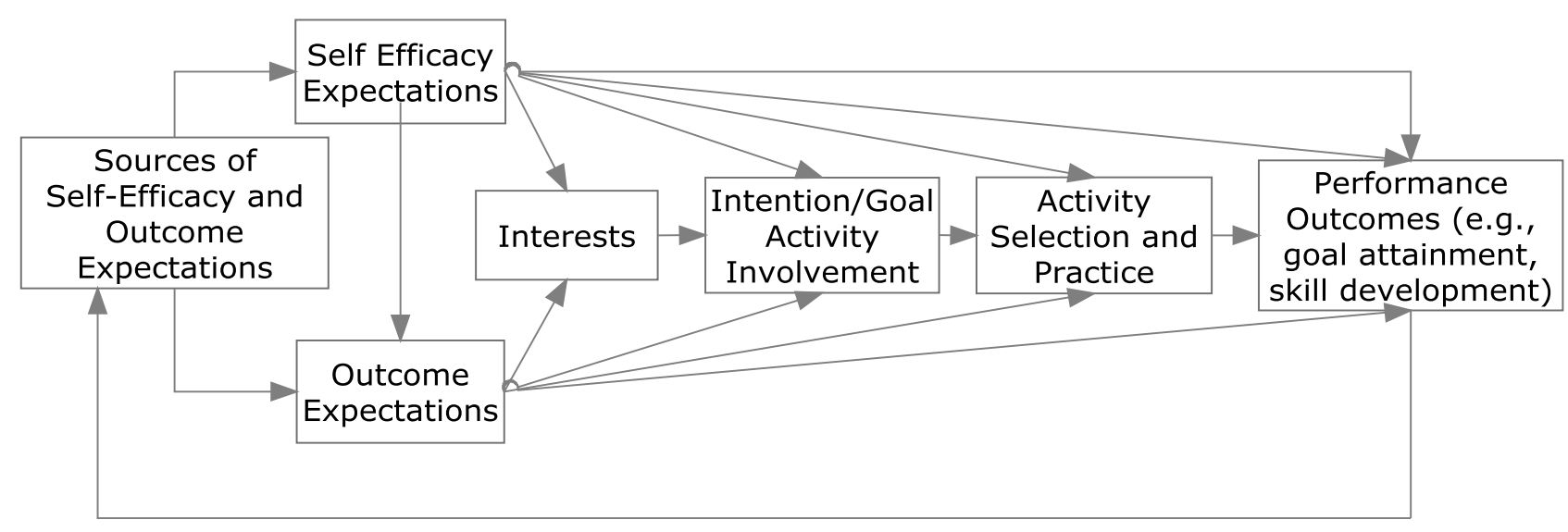

Figure 2. Social Cognitive Career Theory model. (Lent et al., 1994)

Beyond academic and behavioral risks, the literature suggests that powerful identity beliefs affect performance. This, in turn, affects self-efficacy related to pursuing STEM information and choosing a career (Schunk, 1989). These beliefs are based on information received from performances; therefore, students use their own academic achievements as guides for efficacy. According to Schunk (1989), success raises efficacy and failure lowers it. However, "failure" is also seen by businesses as necessary for persistence in problem-solving and continued learning (Woods, 2015). According to Bandura (1993), self-efficacy beliefs affect four major mental processes such as cognitive, motivational, affective, and selection processes, making self-efficacy the foundation for human well-being and sense of personal accomplishment. Bandura (1997) extends this concept to say that people's level of motivation to achieve is based more on what they believe, rather than what is objectively true. Therefore, the 
beliefs that people have about their capabilities may be better predictors of performance than actual competence.

Many regard the Theory of Planned Behavior (TPB) (Ajzen, 1991) as the dominant account of the association between how a person thinks and the resulting behavior (Cooke \& Sheeran, 2004). According to TPB, a human behavior like choosing a STEM college major and earning a degree is influenced by three major factors: a favorable or unfavorable evaluation of the behavior, perceived social pressure to perform or not perform the behavior, and self-efficacy in relation to the behavior (Ajzen, 1991). TPB takes self-efficacy one step further by considering external resources like the availability of time and money that may be needed to successfully perform the behavior (Ajzen, 1991). Thus, attitude toward the behavior, subjective norms (what others think about the behavior), and the perception of behavioral control all lead to the formation of a behavioral intention. The more favorable the attitude, subjective norm, and perceived behavioral control, the stronger the person's intention to perform the behavior. The intent to perform a behavior related to STEM learning is what educators and practitioners are seeking in today's technological world. TPB is also accompanied with precise advice on the construction of questionnaire items. The lead researcher kept this advice in mind, along with the above relationships among the constructs in the creation of STEM IQ items.

\section{Purpose of the Study}

The purpose of this study is to refine and improve the STEM IQ. This instrument was used a part of an evaluation of the Rocket Project. Four hundred and ninety two $(n=492)$ participants answered this questionnaire about their experiences following the program's annual major culminating event which the launching of rockets in May 2014. These students were positive about the experience. However, a preliminary analysis of the factor structure of the instrument indicates that the questionnaire items may not match the theoretical model that served as the frame for the instrument. Additionally, participants were extremely positive about the program, so the data are highly skewed.

The main focus of this study in progress is to test and improve the psychometric properties and theoretical structure of the instrument by following a rigorous procedure for exploring the characteristics and attitudes of program participants via both EFA and confirmatory factor analysis (CFA). The study has three main questions, and they are as follows;

1. Are the four factors in STEM IQ clearly identifiable constructs as measured by the items that they are comprised of?

2. Do the STEM IQ instrument accurately measure each factor?

3. Do relationships exist among the latent constructs (e.g., career, learning transfer, teamwork, active learning)? 


\section{Method}

\section{Sample}

The data were collected in conducted May 2014 with the total of four hundred and ninety two $(n=492)$ students encompassing both males $(n=369)$ and females $(n=118)$. Some students $(n=5)$ did not indicate their gender in the study. Table 1 shows a details information about the participants' demographics.

Table 1

Participants' demographics

\begin{tabular}{lrcc}
\hline Category & & Number $(\mathrm{N})$ & Percentage (\%) \\
\hline Gender (n=492) & & & \\
& Male & 369 & 75 \\
& Female & 118 & 24 \\
Missing & 5 & 1 \\
\hline Race $(\mathrm{n}=492)$ & & & \\
& White & 259 & 52.6 \\
& Hispanic & 175 & 35.6 \\
& African American or Black & 29 & 5.9 \\
& Asian & 10 & 2 \\
International & 8 & 1.6 \\
& Native American & 7 & 1.4 \\
Missing & 4 & .8 \\
\hline
\end{tabular}

\section{Instrumentation}

The 2014 version of the STEM IQ consisted of 71 items. 13 were demographic, 58 attitudinal items related to students' experiences, teamwork, learning experience, hands on active learning, and career. The study focuses on only attitudinal items with a high reliability Cronbach alpha $(\alpha=.83)$. The items in the questionnaire are based on 100 scale. Further, the attitudinal items are divided into three components. First component aims to measure STEM-related selfefficacy, like a student's ability to complete academic milestones and to overcome performance hurdles. Students are asked to indicate their confidence to perform successfully academic tasks related to SystemsGo program's targets. Students are also asked to indicate their ability to cope with problems encountered in producing a rocket. A second component of instrumentation is measures of STEM outcome expectations. Here, respondents will rate what they expect the impact of a STEM career would have on them. A third set of measures is to examine students' technical interests related to STEM, like teamwork, problem-solving, and planning. Students are asked about the role of their environmental support systems, including parents, peers, and teachers. The revised STEM IQ instrument is given in Appendix A. 


\section{Data Collection}

The STEM IQ was administrated and secured in Qualtrics Survey Software, an online survey service, by the lead researcher. All participants were assured that their responses would remain anonymous and confidential, and participation was voluntary. Data were exported from Qualtrics to Excel file, and then in SPSS 18 program for analysis.

\section{Data Analysis}

Factor analysis was used as the analysis technique to investigate the psychometric properties of the STEM IQ. This process began with exploration of statistical assumptions, including tests and corrections for univariate and multivariate normality. The item set was first be reduced with exploratory factor analysis (EFA). Then, the resulting instrument's structure was tested for theoretical frame fidelity using confirmatory factor analysis (CFA). Further, CFA is used to define and describe the degree of model fit, the strength of the factor loading, and the standardized residuals and variances for the hypothesized model variables.

Figure 3 presents the hypothesized model for this study. Rectangles signify observed variables, and ellipses signify latent constructs. Curved double-headed arrows specify correlations between latent constructs. If there is a poor model fit, further refinement is used to find the best fit model on to compute latent-variable final models (Anderson \& Gerbing, 1988). SPSS 18 is used to compute the statistical analysis for EFA. The data include missing data (7.7\%); therefore, the researchers used the Multiple Imputation technique in SPSS 18 to impute the data. AMOS 18 statistical software is used to estimate confirmatory factor model (e.g., Arbuckle, 2005; Byrne, 2001). 


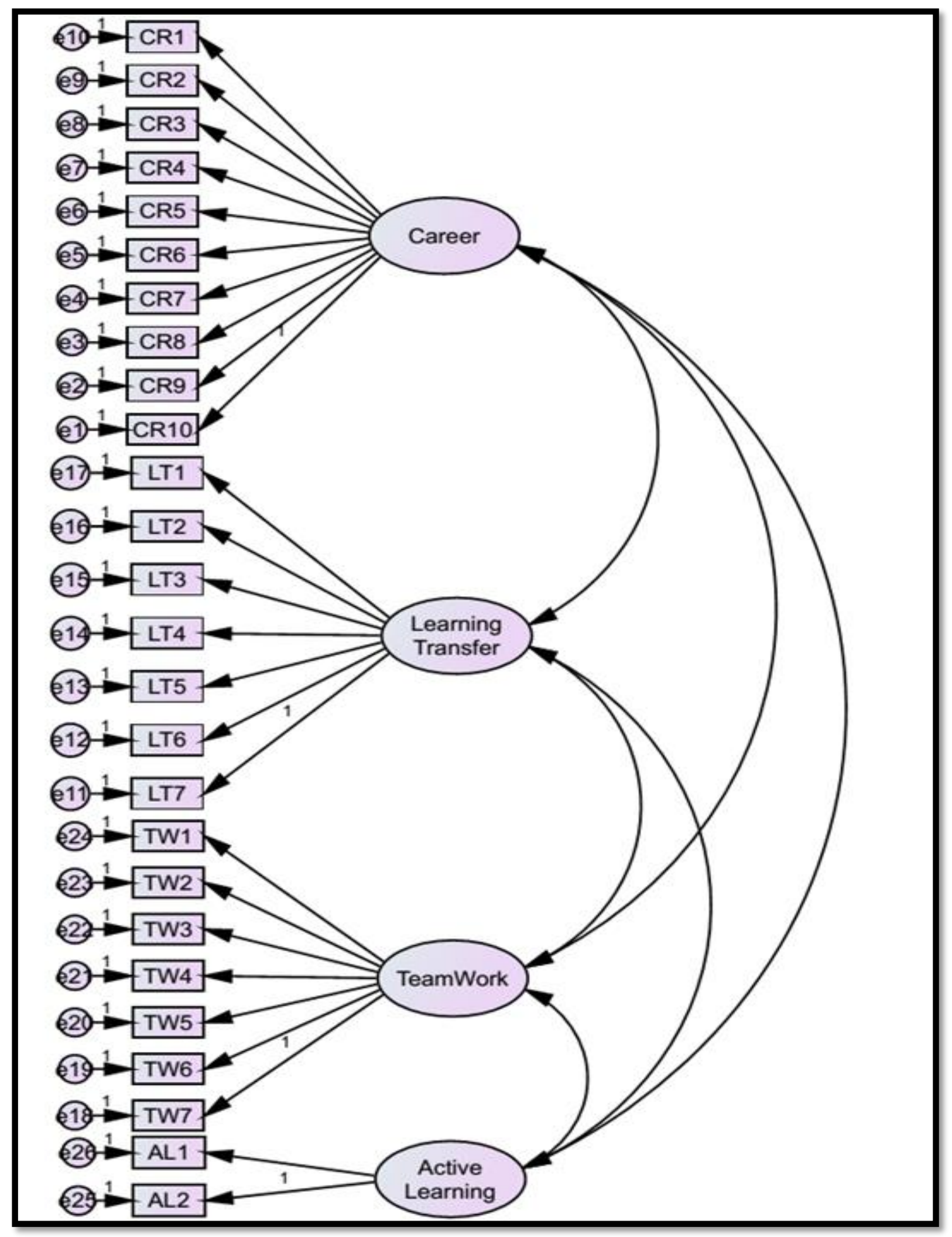

Figure 3. Hypothesized Model 


\section{Results}

As a result of an EFA, the researcher retained four factors with eigenvalues greater than one based on Kaiser's suggestion (1960). Out of 58 items, 22 items fall off, and 26 items remained and had a significant factor loadings onto one of the four factors with a factor loading greater than .40 as a cutoff factor loading (Steven, 2002) that designating each item's distinctive influence to one of the factors. The first factor with items was labeled as Career (CR), second Learning Transfer (LT), third Teamwork (TW), and fourth Active Learning (AL) with 10, 7, 7 , and 2 items, respectively. As extraction method, Principal Axis Factoring was used. In terms of Rotation method, Promax with Kaiser Normalization technique was used. The rotation converged in 6 iterations.

As a result of CFA, there are 48 variables in the hypothesized model, 26 exogenous (i.e., unobserved) and 22 endogenous (i.e., observed). Table 2 presents the regression weights and the standardized regression weights for the final model. All coefficients associated with paths linking the model's exogenous and endogenous variables, and all are significant by the critical ratio test $(\mathrm{p}<.05)$.

Figure 4 shows the standardized covariances have been integrated into the final model. Learning transfer and career has the highest covariance $(\beta=.68)$. Also, covariance between learning transfer and teamwork, career and teamwork, active learning and teamwork, active learning and career, and learning transfer and active learning is .66, .59, .53, .51, and .46, respectively.

In the hypothesized model (see Figure 3), there were 26 items, however, in the final model (see Figure 4), 1 item (i.e., CR5) from career and 3 items (i.e., LT 1, 2, 4) from learning transfer removed in order to make the best fit indices. Consequently, the final model has 22 measured variables with the set of 253 sample moments. The model contains 50 parameters to be computed, therefore, has 203 (253-50) degrees of freedom, and yielded to a significant chisquared (see Table 2) value of

$$
\chi^{2}(\mathrm{~N}=492, \mathrm{df}=203)=673.220, \mathrm{p}<.05
$$

Table 2

Computation of Degrees of Freedom and Chi-Square Statistics for Goodness-of-Fit

Parameter Summary

\begin{tabular}{lcccccc} 
& Weights & Covariances & Variances & Means & Intercepts & Total \\
\hline Fixed & 26 & 0 & 0 & 0 & 0 & 26 \\
Labeled & 0 & 0 & 0 & 0 & 0 & 0 \\
Unlabeled & 18 & 6 & 26 & 0 & 0 & 50 \\
Total & 44 & 6 & 26 & 0 & 0 & 76 \\
\hline
\end{tabular}


Computation of degrees of freedom

\begin{tabular}{lr}
\hline Number of distinct sample moments & 253 \\
Number of distinct parameters to be estimated & 50 \\
Degrees of freedom (253-50) & 203 \\
\hline
\end{tabular}

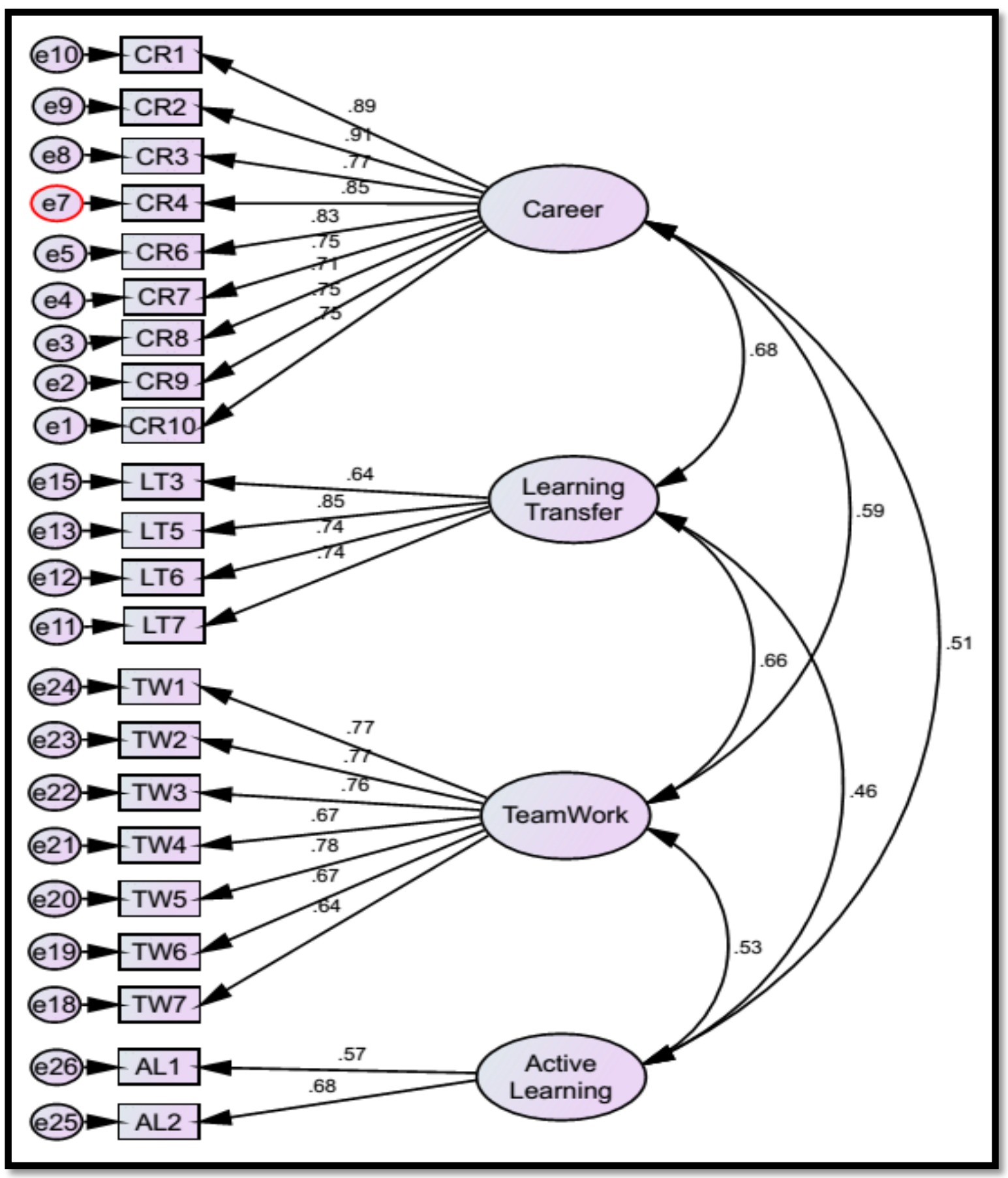

Figure 4. Standardized Final Model 
Table 3 show the chi-square goodness-of-fit statistics, baseline comparison fit indices, and model comparison statistics for hypothesized and final models. Although the chi-square values for both models are statistically significant, the baseline comparison fit indices of NFI, RFI, IFI, and CFI for both models are close or above .9 which is between .890 and .931 . These values indicate that the improvement in fit of both models relative to the null model.

As a good indicator to determine the fit indices is to look at root mean square error of approximation (RMSEA) which includes the error of approximation in the population. The RMSEA value for the final model is .069 which indicates an acceptable range (Browne \& Cudeck, 1993; MacCallum, Browne, \& Sugawara, 1996). This value suggests that the fit of the model is in a satisfactory level.

Another very useful fit index is to use the AIC statistics (Akaike, 1973; 1987). The AIC determines the hypothesized and final models' thriftiness and fitting. As it is shown in Table 3 AIC, the ACI value of default model (773.220) is higher than saturated model (506.000) which indicates that the saturated model is a better fitting model than default model, and further statistical results and standardized hypothesized model output are given in Appendix B and C, respectively.

Table 3

Direct and indirect Models' Chi-Square Goodness-of-Fit Indices, Baseline and Model Comparison

\begin{tabular}{lrrrrr}
\hline Model & NPAR & CMIN & DF & P & CMIN/DF \\
\hline Default & 50 & 673.220 & 203 & .000 & 3.316 \\
Saturated & 253 & .000 & 0 & & \\
Independence & 22 & 6971.883 & 231 & .000 & 30.181 \\
\hline
\end{tabular}

Baseline Comparison

\begin{tabular}{lrrrrr}
\hline Model & NFI Delta 1 & RFI rho 1 & IFI Delta2 & TLI rho2 & CFI \\
\hline Default & .903 & .890 & .931 & .921 & .930 \\
Saturated & 1.000 & & & & 1.000 \\
Independence & .000 & .000 & .000 & .000 & .000 \\
\hline
\end{tabular}

RMSEA

\begin{tabular}{lrrrr}
\hline Model & RMSEA & LO 90 & HI 90 & PCLOSE \\
\hline Default & .069 & .063 & .074 & .000 \\
Independence & .244 & .239 & .249 & .000 \\
\hline
\end{tabular}


AIC

\begin{tabular}{lrrrr}
\hline Model & AIC & BCC & BIC & CAIC \\
\hline Default & 773.220 & 778.134 & 983.144 & 1033.144 \\
Saturated & 506.000 & 530.868 & 1568.215 & 1821.215 \\
Independence & 7015.883 & 7018.045 & 7108.250 & 7130.250 \\
\hline
\end{tabular}

\section{Discussion}

From the results of this study, the domain specific version of the revised instrument appears to measure the construct of career, learning transfer, teamwork, and active learning reasonably well when examining their respective models for the total baseline sample. The more positive interests towards STEM, the greater likelihood the students will aim in STEM career.

The results using CFA supported the four factor structure of the STEM IQ itself. Although the conclusion obtained resulted in a statically significant chi-square values of $\chi^{2}=$ $673.220(\mathrm{~N}=492, \mathrm{df}=203, \mathrm{p}<.05)$, several goodness-of-fit values $(\mathrm{RMSEA}=.069, \mathrm{CFI}=.930)$ indicative of good fit for the proposed theoretical model (Ho, 2006). Further, correlations in the hypothesized model between the latent constructs of the STEM IQ were supported. Overall, these results indicate study refines further the STEM IQ instrument. Thus, the testing of the competing values model and a refined operationalization of it was very successful.

Future research should examine the practical significance of the STEM IQ instrument in predicting actual STEM interest with other students involved in STEM projects (e.g., Robotics) from the theoretical and psychometric findings of this study. The instrument, STEM IQ provides a psychometric and theoretical foundation from which this future research may be conducted.

\section{Implications for Practice in K-12}

The program outcomes are varied and come at the short term and the long term. At the base level, students built rockets that met certain criteria. They also developed a heightened interest toward STEM, develop improved teamwork skills, and develop more expert-level understanding of how to use failures and successes as part of a continual improvement cycle. STEM IQ may help researchers, educators, and policy makers better understand how students are influenced by problem-based learning instruction, for example, dealing with real world experiences, like creating and preparing craft for spaceflight. Instead of seeing the "failure" associated with reoccurring problems in the aerospace environment, they are more readily understood as learning experiences for their future STEM careers.

Note: This research was supported and funded partially by SystemsGo, Inc. www.systemsgo.org. We thank Mr. Brett Williams, founding teacher and former executive director of SystemsGo, and the entire SystemsGo group for allowing us to observe students and teachers in their program. 


\section{Selected References}

Ajzen, I. (1991). The theory of planned behavior. Organizational Behavior and Human Decision Processes, 50, 179-211.

Anderson, J. C., \& Gerbing, D. W. (1988). Structural equation modeling in practice: A review and recommended two-step approach. Psychological Bulletin, 103 (3), 411-423.

Arbuckle, J.L. (2006). Amos 7.0 User's Guide, Chicago, IL: SPSS Inc.

Armitage, C. \& Conner, M. (2001). Efficacy of the Theory of Planned Behavior: A meta-analytic review. British Journal of Social Psychology, 40, 471-499.

Bandura, A. (1986). Social foundations of thought and action: A social cognitive theory. Englewood Cliffs, NJ: Prentice-Hall.

Bandura, A. (1993). Perceived self-efficacy in cognitive development and functioning. Educational Psychologist, 28 (2) 117-148.

Bandura, A. (1997). Self-efficacy: The exercise of control. New York: Freeman.

Byrne, B. M. (2001). Structural equation modeling with AMOS-Basic concepts, applications, and programming. LEA, ISBN 0- 8058-4104-0.

Cooke, R., \& Sheeran, P (2004). Moderation of cognition-intention and cognition-behavior relations: A meta-analysis of properties of variables from the theory of planned behavior. British Journal of Social Psychology, 43, 159-156.

Lapan, R. , Shaughnessy, P., \& Boggs,K. (1996). Efficacy expectations and vocational interests as mediators between sex and choice of math/science college majors: A longitudinal study. Journal of Vocational Behavior, 49, 277-291.

Lent, R. W., Brown, S. D., \& Hackett, G. (2002). Social cognitive career theory. Career choice and development, 4, 255-311.

Lent, R. W., Brown, S. D., Schmidt, J., Brenner, B., Lyons, H., \& Treistman, D. (2003). Relation of contextual supports and barriers to choice behavior in engineering majors: Test of alternative social cognitive models. Journal of Counseling Psychology, 50(4), 458.

Lips, H.M. (1992). Gender and science-related attitudes as predictors of college students' academic choices. Journal of Vocational Behavior, 40, 62-81.

Schunk, D. (1989). Self-efficacy and achievement behaviors. Educational Psychology Review, 3, 173-289.

Woods, D. D. (2015). Four concepts for resilience and the implications for the future of resilience engineering. Reliability Engineering \& System Safety. 
Young, D., \& Ley, K. (2001).Developmental students don't know that they don't know. Part II, bridging the gap. The Journal of College Reading and Learning, 31 (2), 171-178.

Young, D., \& Ley, K. (2002). Brief report: self-efficacy of developmental college students. The Journal of College Reading and Learning, 33 (1), 21-24. 


\section{Appendix A}

\begin{tabular}{|c|c|c|c|}
\hline Themes & Item & No & Item Description \\
\hline \multirow{10}{*}{ Career } & Q25_1 & CR1 & For me to have a STEM career would be \\
\hline & Q24_1 & CR2 & For me to excel in a STEM career would be highly enjoyable \\
\hline & Q41_2 & CR3 & At the end of this year, I want to choose a STEM career. \\
\hline & Q29_1 & CR4 & $\begin{array}{l}\text { My experience with the rocket program makes me want to choose a } \\
\text { STEM career. }\end{array}$ \\
\hline & Q41_1 & CR5 & $\begin{array}{l}\text { Before I started the rocket program, I wanted to choose a STEM } \\
\text { career. }\end{array}$ \\
\hline & Q35_3 & CR6 & $\begin{array}{l}\text { I am certain that I will find satisfying any work that uses science, } \\
\text { technology, or engineering. }\end{array}$ \\
\hline & Q35_1 & CR7 & I know I will earn an attractive salary in a STEM career. \\
\hline & Q31_1 & CR8 & For me to become an engineer is entirely possible. \\
\hline & Q26_1 & CR9 & For me to excel in a STEM career would be very easy \\
\hline & Q35_4 & CR10 & $\begin{array}{l}\text { Using what I've learned from the rocket program, I am certain I will } \\
\text { build things that have a lasting effect on society. }\end{array}$ \\
\hline \multirow{7}{*}{$\begin{array}{l}\text { Learning } \\
\text { Transfer }\end{array}$} & $\begin{array}{l}\text { Q36_3_- } \\
\text { recode }\end{array}$ & LT1 & The entire experience was fantastic. \\
\hline & Q36_2 & LT2 & The teaching helped me become a more effective problem-solver. \\
\hline & Q36_1 & LT3 & I learned an incredible amount about many things. \\
\hline & $\begin{array}{l}\text { Q36_4_- } \\
\text { recode }\end{array}$ & LT4 & I would recommend this type of program for all high schools. \\
\hline & Q36_6 & LT5 & $\begin{array}{l}\text { No matter what career I choose, I will be able to use what I have } \\
\text { learned in the rocket program. }\end{array}$ \\
\hline & Q36_7 & LT6 & I have used what I learned in the rocket program in other classes. \\
\hline & Q36_5 & LT7 & This program helped me clarify my career goals. \\
\hline \multirow{7}{*}{$\begin{array}{l}\text { Team } \\
\text { Work }\end{array}$} & Q40_7 & TW1 & I help people see how to break up task into small parts. \\
\hline & Q40_6 & TW2 & Often, I show my teammates how to get started on a task. \\
\hline & Q40_5 & TW3 & $\begin{array}{l}\text { When my team starts to drag, I think of something to say to get the } \\
\text { energy back. }\end{array}$ \\
\hline & Q40_8 & TW4 & $\begin{array}{l}\text { If I see a teammate making a mistake, I know how to help him/her } \\
\text { without making him/her embarrassed. }\end{array}$ \\
\hline & Q40_4 & TW5 & I take an active role in briefings to share our progress and ideas. \\
\hline & Q44_2 & TW6 & $\begin{array}{l}\text { At the end of this year, I am confident that I can help a team stick to } \\
\text { deadlines. }\end{array}$ \\
\hline & Q40_1 & TW7 & $\begin{array}{l}\text { Before I started the rocket program, I wanted to choose a STEM } \\
\text { career. }\end{array}$ \\
\hline \multirow{2}{*}{$\begin{array}{l}\text { Active } \\
\text { Learning }\end{array}$} & Q21_3 & AL1 & I work on machines (like car engines) for fun. \\
\hline & $\begin{array}{l}\text { Q21_1_- } \\
\text { recode }\end{array}$ & AL2 & I love working with my hands. \\
\hline
\end{tabular}




\section{Appendix B}

\begin{tabular}{rrrr} 
& Chi-squared & Degree of freedom & Probability level \\
\hline Result & 673.220 & 203 & 0.000 \\
\hline
\end{tabular}

Covariances

\begin{tabular}{lrrrrr}
\hline Model & Estimate & S.E. & C.R. & P & Label \\
\hline Career $<->$ Learning Transfer & 352.761 & 36.306 & 9.716 & $* * *$ & \\
Career $<->$ Teamwork & 193.131 & 22.504 & 8.582 & $* * *$ & \\
Career $<->$ Active Learning & 131.222 & 18.293 & 6.935 & $* * *$ & \\
Learning Transfer $<->$ Teamwork & 231.139 & 26.127 & 8.847 & $* * *$ & \\
Learning Transfer $<->$ Active Learning & 128.217 & 20.486 & 6.259 & $* * *$ & \\
Teamwork <-> Active Learning & 93.614 & 13.787 & 6.790 & $* * *$ & \\
\hline
\end{tabular}

Correlations

\begin{tabular}{lr}
\hline Model & Estimate \\
\hline Career $<->$ Learning Transfer & .685 \\
Career $<->$ Teamwork & .589 \\
Career $<->$ Active Learning & .505 \\
Learning Transfer $<->$ Teamwork & .662 \\
Learning Transfer $<->$ Active Learning & .464 \\
Teamwork $<->$ Active Learning & .532 \\
\hline
\end{tabular}


Appendix C

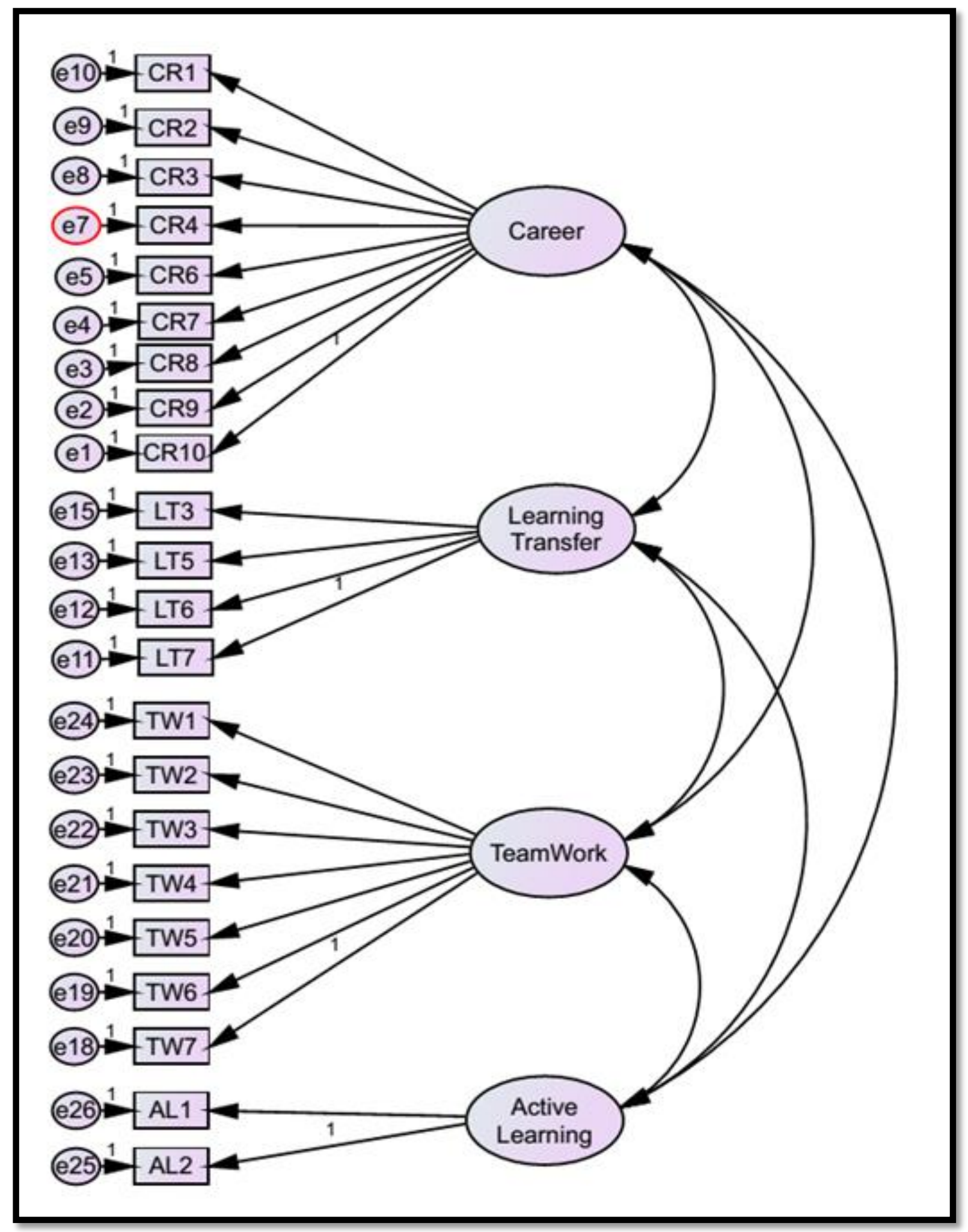

Figure 5. Final Model 


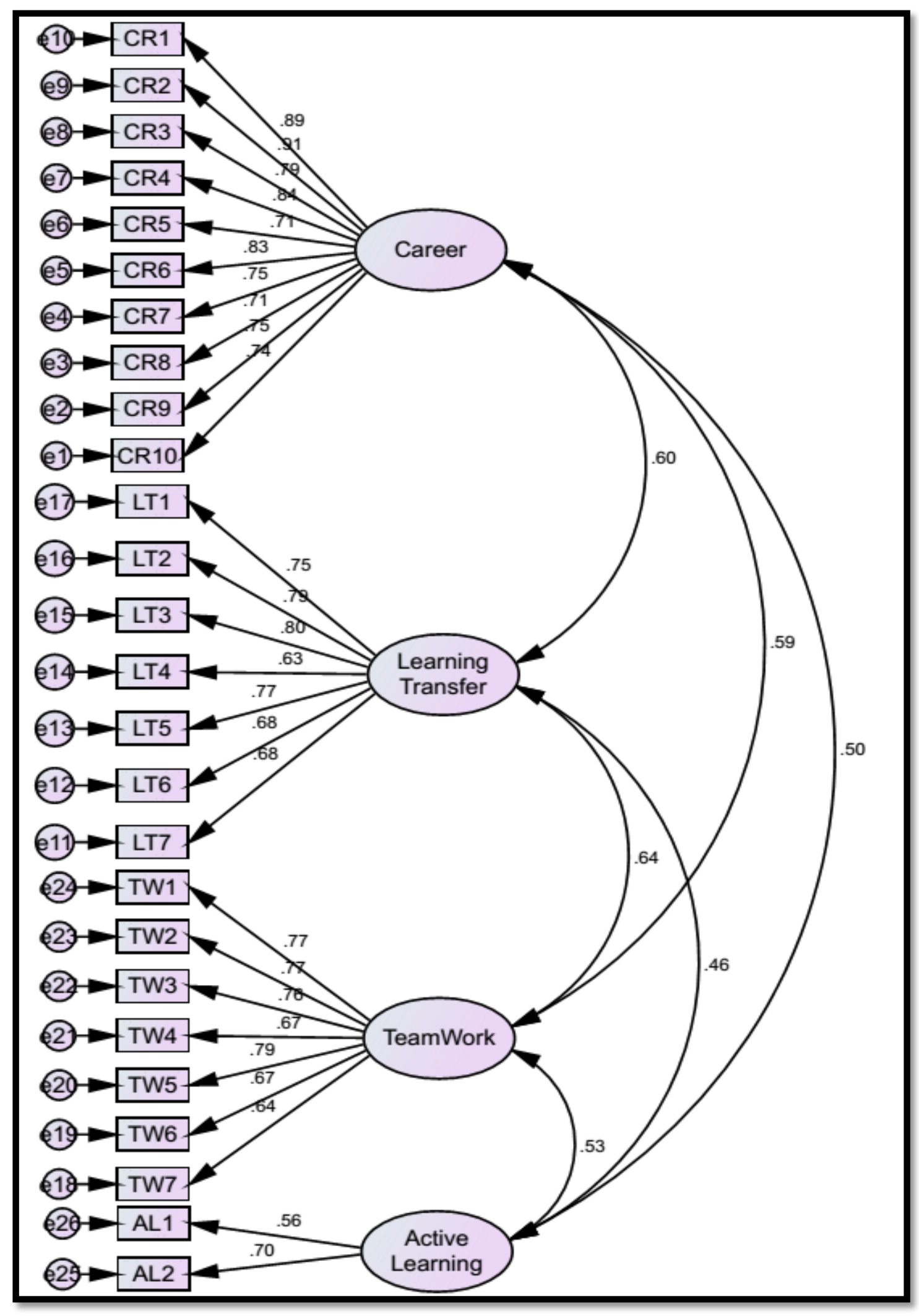

Figure 6. Standardized hypothesized Model Output 